\title{
Team Based Learning: A controlled trial of Active learning in Large Group Setting.
}

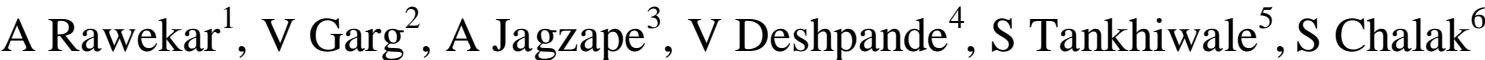 \\ ${ }^{1}$ Associate Professor, Physiology, Jawaharlal Nehru Medical College. DMIMS (Deemed University)India. \\ ${ }^{2}$ Assistant Professor, Physiology. Sham Shah Medical College, Rewa, M. P. India. \\ ${ }^{3,6}$ Assistant Professor, Physiology, Jawaharlal Nehru Medical College, DMIMS (Deemed University) India. \\ ${ }^{4}$ Director Professor, Physiology, Jawaharlal Nehru Medical College, DMIMS (Deemed University)India. \\ ${ }^{5}$ Director, Center for Health Professionals Education, DMIMS (Deemed University) India..
}

\begin{abstract}
Objectives: The aim and objectives of intervention with Team Based Learning (TBL) was to foster active learning environment in large group teaching and to obtain their perception on team work.

Methods: It was single blind controlled interventional study conducted at Jawaharlal Nehru Medical College Sawangi (Meghe), Wardha, India. First MBBS students of second semester were enrolled for the study. Thirty five students $(n=35)$ were randomly divided in 5 teams of 7 members each. The TBL program was introduced as supplement to the traditional instructional methodology in Physiology by taking 2 modules.

Perception of students on TBL, teamwork and preference to TBL was obtained. Quantitative analysis was done by comparing the scores in preliminary examination between study and control group. The Students " $t$ " test was applied to find out significance.

Results: Results showed that most of the students were agreed for this type of instructional strategy as it enriched their knowledge and find relevant for the subject Physiology. While comparing these sessions with classroom lecture method, students were of opinion that TBL was better than lecture. There was overall increase in marks obtained in examination.
\end{abstract}

Conclusion: TBL was successfully introduced and well accepted with 2 modules in Physiology promoting selfdirected learning.

Keywords - Active learning, Large group teaching, Self directed learning, Team based learning.

\section{Introduction}

Teaching physiology can be challenging because it is easy to overwhelm students with information. The traditional approach of teaching physiology as a lecture course is efficient in that it allows the teacher to present a large amount of information to many students. The downside of this approach is that it fosters passive learning where students expect to be told what to learn and how to learn it. Students do not develop the skills or the interest to learn on their own, and enthusiasm for the course is low.

It is clear that learning styles of students in medical schools are diverse. Thus, at best, the lecture format reaches only a select group of students and in-depth understanding of key concepts such that students have difficulty applying these concepts in new contexts. These points raise the question of how we can change our mode of instruction so that students acquire the information base they need, but they also engage in the genuine inquiry that is at the heart of the scientific process.

Many different methods to motivate and engage students have been developed and tested for different classes, especially in the sciences [1]. One such invention is the teaching team model for large lecture classes, a model that is closely aligned with the recommendations of the Boyer Commission on Educating Undergraduates in the Research University (1998) for improving undergraduate education [2].

Team-based learning (TBL) is an instructional strategy originally developed by Dr. Larry Michaelsen for business courses, and recently, medical schools have been adopting this strategy. In the last few years, numerous medical schools adopted TBL in the delivery of basic sciences [3], clerkships and the residency programs [4].

\section{Rationale of study:}

Developments during the last two decades have made many college classrooms less supportive environments for student learning. At present the number of full-time colleges in India is 355 with an approximate intake of students per year is 43,740. Between the years 2008 to 2011-12 there is $32 \%$ increase in intake of students per year from 30,000 to 43,740 [5]. Similarly between 1990 and 2005 the number of college students in the United States increased by 38\% from 13.8 million students in 1990 to 17.5 million in 2005[6]. Due to budget cuts faced by many colleges and universities, this trend contributed to an overall increase in class sizes in introductory college classes at public universities [6]. At the same time students were shifting toward a 
consumer attitude regarding their education, tending to become more passive in their learning and less engaged in the classroom [7]. This combination of effects presents both a teaching challenge for faculty and a learning challenge for many students.

Health has always been about teamwork. In Lancet Commissions Report 2010, it is affirmed that for interprofessional education, health needs teamwork, and this necessity has grown in importance because of the transformation of health systems. While dealing with non-communicable diseases or infectious diseases, it requires command and control teams of multidisciplinary professionals like doctors, nurses, social workers, counselors etc. Consequently Medical schools are now creating integrated and interdisciplinary courses during the preclinical years [8].

Hence, the Team based learning (TBL) was introduced aiming at preparing students for active, collaborative learning within a cohesive group. The study was conducted as an instructional approach in Physiology with the following objectives:

- $\quad$ to evaluate students' perceptions of Team - Based Learning

- to evaluate students' perception on teamwork (Interpersonal and team interaction skills)

- to develop students' ability to use course concepts in thinking and problem solving.

\section{Materials and Methods:}

2.1. Ethics committee Approval: The study was conducted after obtaining approval from Institutional Ethics Committee.

2.2. Study design: This was Single blind; controlled interventional study.

2.3. Sampling: Students of $2^{\text {nd }}$ semester of first profession $\left(1^{\text {st }}\right.$ MBBS) were taken for study. Scores in first formative assessment were taken as selection criteria. Out of 150, first 100 students were appealed to participate for this new instructional approach as it was not the traditional one. Accordingly 35 students (Females $=19$, Males =16) gave the informed written consent. They were all introduced to this new intervention as augmented teaching strategy to enhance their problem solving skill in collaborative style. Similarly age and sex matched 35 students were taken as control group (Females $=19$, Males $=16$ ).

\subsection{Study instrument:}

Three Standard Questionnaires were prepared on Perception of TBL (8 items), Perception on teamwork (7 items), and Preference for TBL ( 9 items) on a 5 point likert scale ( $1=$ strongly disagree to $5=$ strongly agree). All questionnaires were validated.

\subsection{TBL Activity:}

The TBL intervention was used as supplement to the traditional instructional methodology in Physiology. The 35 students who enrolled for the study were randomly divided into 5 teams of 7 each. The same team retained for all the sessions

Four TBL sessions on two modules were conducted. Two topics from Respiratory and Excretory System of clinical relevance and with similar difficulty level were selected after consulting other colleagues in the department (Hyaline Membrane Disease and Nephrotic Syndrome).

TBL sessions were scheduled for 4-week timeframe. The concepts of TBL, making the groups and discussing the learning objectives of both the modules were introduced 2 weeks in advance to the students of interventional arm. Session on TBL included all elements of TBL: Individual Readiness Assurance Test (IRAT); Group Readiness Assurance Test (G-RAT), and Group Application Process (GAP).

First session was conducted with test on the assigned topic (Hyaline membrane disease) comprising 10 MCQs (with difficulty level I and II) to be answered individually (I-RAT). The scores were given. Then the same test was given to all 5 groups and as a group activity they solved these questions with consensus and came out with the answers (G-RAT). These answers were discussed again by all groups with necessary inputs by the facilitator. Accordingly the marks were given to the groups. These two tests ensured that the students were prepared.

During the second session, a case scenario on Hyaline membrane Disease was given to each group. At the end of this case, 4-5 questions were asked whose answers needed discussion amongst the group members. The time given for discussion was around $30 \mathrm{~min}$. Once the group was ready with the answers, the answers were again discussed amongst the groups (GAP). Whenever there was disagreement of opinion, facilitator helped them to solve those controversies. The facilitator was ready with a power point presentation about each topic to make necessary clarifications to the students about any doubts that emerges during the discussion.

A second topic (Nephrotic Syndrome) of similar depth, weightage and difficulty level was chosen and sessions were conducted in same manner. 
After completion of both the modules, a perception of students was taken on TBL as a learning tool. Performance in the preliminary examination was used to measure the impact of team-learning activities on the students' retention and understanding of concepts (topics covered through TBL).

2.6. Statistical Analysis:

Qualitative and quantitative data analysis was carried out.

- For qualitative analysis, a Cronbach's alpha was applied to find out the internal consistency of each item in all the three questionnaires.

- Quantitative analysis was done by comparing the mean scores obtained in preliminary examination in study and control group. The Students "t" test was applied to find out the statistical difference between the mean scores of both the groups. A $p<0.05$ was considered statistical significant.

\section{Results:}

\subsection{Qualitative results:}

Three questionnaires were developed on Perception of TBL; Perception on teamwork and Preference for TBL. Students' responses to items in these questionnaires recorded on a 5 point Likert scale were expressed as percentages. The response rate for all the questionnaires was $100 \%$.

\subsubsection{Perception of TBL}

All the students agreed that TBL created interest in the subject Physiology. Of the students, $83 \%$ agreed that TBL helped in preparation of course content, $79 \%$ students were of opinion that TBL helped them to understand the course material, 53\% agreed and 12\% strongly agreed that TBL was useful for developing synthesizing skills. About I-RAT, 67\% students were agreed and 33\% were strongly agreed that it was useful learning activity (Table 1).

\subsubsection{Perception on teamwork}

As a team, it worked well together, $33 \%$ strongly agreed and $67 \%$ agreed for this point. Of the students, $100 \%$ students were of opinion that they had mutual respect for team-mates and positive attitude about working with their peers. Overall, 51\% students were of opinion that their ability to collaborate with peers was necessary to become successful student, while $100 \%$ students felt that solving problems in groups was proved to be an effective way of practice what they read or learn (Table 2).

\subsubsection{Preference for TBL}

When asked for preparedness of individual test and completion of required reading $77 \%$ were agreed for that. While comparing these sessions with classroom lecture, $83 \%$ said that TBL was better than lecture format of teaching. Overall 100\% students were of opinion that the group discussion improved their understanding of concepts and solving problems was an effective way to learn Physiology (Table 3).

\subsubsection{Reliability:}

A principal components factor analysis with varimax rotation was analyzed for three questionnaires with 8, 7, 9-item factors on: "Perceptions of TBL", "Perceptions on teamwork" and "Preference for TBL" respectively.

Internal consistency for each was high giving high reliability. [Cronbach's alpha $=0.908$ (Perceptions of TBL); 0.884 (Perceptions of teamwork); 0.892 (Preference for TBL)].

\subsection{Quantitative results:}

The results of quantitative assessment in preliminary examination showed relative increase in scores but the difference between mean score was not statistically significant $(\mathrm{p}=0.132)$. The paper setter and valuer for this examination were blind for the details of this intervention, giving validity to the study results (Table 4).

\section{Discussion:}

Many active-learning activities have been developed to improve basic science instructions. Various methods have been used to reinforce didactic instructions in Physiology such as Problem based learning, multiple format sessions etc. In turn, innovative teaching is primarily geared towards enhancing students' critical thinking, thus grooming 'individuals to become independent lifelong learners'. In its application, innovative teaching can take different forms; examples being team learning, problem-based learning (PBL) etc.

Introduction of the intervention in the form of Team Based Learning (TBL) was tried to integrate the knowledge of Physiology with clinical Medicine[9]. In TBL, students go through the clinical settings, learn about the tasks, understand the concepts and mechanisms underlying those tasks, apply their knowledge and skills in different contexts, and acquire general competences. Learning objectives in TBL are more explicit than 
in PBL. The students usually learn individually in the TBL strategy [10,11]. It offers an opportunity to increase the relevance of clinical learning to clinical practice. We used TBL as an augmenting strategy of learning to develop critical thinking and problem solving abilities. The objectives of this study were to evaluate the usefulness and perception of students towards this innovation.

Four Key TBL Design Principles were kept in mind while implementing this intervention.

1. Teams should be diverse and permanent (5-7 members in each team)

2. Accountability $\mathrm{f}$ or student pre-class preparation and contributing to team success.

3. Students make complex decisions that require the use of the course concepts

4. Timely feedback must be given to students.

We evaluated the effectiveness of TBL in physiology by marks obtained in the examination and compared with the control group. There was a relative increase in scores in intervention group but the difference between the mean scores was not statistically significant. As teaching learning involves simultaneous practice of varied type of activities like self study, tutorial, it is impossible to separate the effect of one particular educational activity from myriads of other educational activities [12].

Usefulness of TBL was also assessed by taking students' responses on various attributes of TBL. Consistent with our results, several investigators found that co-operative learning approaches using small groups improved retention and final performances in class $[4,13,14]$. Students were of the perception that they will be able to transfer concepts and information they learned during these sessions and can apply the information in new context. Students also perceived that critical thinking skills and problem solving skills improved while using team based learning. Students who learnt by using this type of method tend to assimilate the content better than students who were not using it according to Clark et al 2008[13] and Haidat et al 2008 [14].

In regard to "working in Teams" our study was in agreement with various studies. According to Clark et al., 2008, teamwork and learning among students is purported to improve with team-based learning [13]. Working in groups exposes students to multiple viewpoints and ideas, in which they gain additional insights from each other; noted by Haidet, 2002 [4]. This creates a learning environment where students teach and learn together, thus maximizing group learning. Students learn how to work as a team to solve problems (McInerney \& Fink, 2003). Additionally, this collaboration and interaction teaches practical interpersonal skills that are helpful in the work environment, particularly in the health care setting [15].

Studies in other disciplines have demonstrated favorable responses of student to team-based learning as we obtained in this study (Seidel \& Richards, 2001 [3]; Touchet \& Coon, 2005 [16]). McInerney \& Fink, 2003 reported that small group activities increased students' enthusiasm for the course and peer interaction increased overall student satisfaction with the course [16]. The students in the present study also perceived the same response.

An additional benefit of using TBL noted by Zgheib et al 2009 [17] and commonly noted among proponents of TBL is that using TBL instead of customary small group discussions was 'cost effective' because only one faculty member was required. Team-based learning allows small groups to interact without requiring multiple educators to be present, unlike other methods such as problem-based learning. Even with large classes of 200 students, team-based learning can be used effectively by one faculty member (Clark et al., 2008). This shift towards placing the responsibility of learning onto the student alleviates faculty burden and allows the faculty member to become a facilitator of learning (Touchet \& Coon, 2005). Though not evaluated but same was the experience of faculty members who were involved in this process. Students attend class more regularly and are better prepared for interacting with the material. This enhances faculty-student interactions, resulting in more fulfilling relationships stated by Michaelsen \& Sweet, 2007 [18].

Matching with the results of present study, some studies indicated that active learning, especially the use of small group activities, improves student performance and enthusiasm in diverse college courses [19,20]. Another aspect of TBL is active engagement strategy of team-based learning which is supported by educational research that has demonstrated that students learn complex concepts better and retain them longer if they are actively involved in the learning process. These findings are supported by research done by Touchet B. 2005 demonstrating that TBL improves critical thinking, comprehension, and information retention[17]. Other research has shown that team-oriented approaches to realistic learning tasks result in improved performance in decision-making even beyond a group's best member's performance. Since TBL is oriented more to declarative than to procedural knowledge, evaluating the impact of TBL on available assessments, scores might begin the process of definitively determining the place of TBL in applied Physiology (Wiener, H 2009) [21].

For any educational intervention, its feasibility and acceptability are at paramount importance. Increasing class size and teacher student ratio, this intervention in the form of introduction of Team Based Learning in Physiology was conducted efficiently and accepted well by students and faculty members. 


\section{Conclusion:}

In conclusion, the TBL format has been successfully introduced with modules of Respiratory and Excretory systems in Physiology with the key objectives of promoting self-directed learning, student accountability, and knowledge application.

It was demonstrated that active learning strategies can be employed in the lecture class without reductions in knowledge acquisition or attitude enhancement by learners. In addition, small-group task solving work within a large-group session will produce more active engagement among learners.

Thus, TBL is a viable active-learning instructional strategy for large student-faculty ratios that could be easily adapted for other courses and curriculums.

\section{Limitations and Scope:}

Inclusion of marks of TBL sessions to the internal assessment marks could have increased the participation of students in this instructional strategy. Adding marks in the internal assessment was beyond the scope of researcher.

Further educational research should be directed toward the factors associated with learner perceptions of teaching value, learning styles and the effects of such perceptions on learning outcomes. The careful alignment of aims, learning outcomes, teaching approaches and assessment methods which is inherent in excellent curriculum design places educators in the best possible position to create an environment that supports student learning.

\section{References:}

[1]. Miller SA, Perotti W, Silverthorn DU. From college to clinic: reasoning over memorization is key for understanding anatomy. Anat Rec. 2002; 269:69-80.

[2]. Boyer Commission on Educating Undergraduates in the Research University, 1998. Boyer Commission on Educating Undergraduates in the Research University. Reinventing Undergraduate Education: A Blueprint for American Research Universities. 1998. http://naples.cc.sunysb.edu/Pres/boyer.nsf. (accessed on May 2012).

[3]. Seidel, C., \& Richards, B. Application of team learning in a medical physiology course. Academic Medicine. 2001; 76:533-534.

[4]. Haidet, P., O’Malley, K., \& Richards, B. An initial experience with "team learning" in medical education. Academic Medicine. 2002; 77: 40-44.

[5]. Medical Council of India. List of Colleges Teaching MBBS http://www.mciindia.org/InformationDesk/MedicalCollegeHospitals/ListofCollegesTeachingMBBS. (cited on 2.9.2012).

[6]. National Center for Education Statistics (NCES), Postsecondary Education Quick Information Survey on Higher Education Finances and Services. Washington, D.C.: 1995. http://nces.ed.gov/pubs95/95393.pdf.(accessed 14 March 2012).

[7]. Lord T. "Darn it, professor. Just tell us what we need to know to pass your course." J. Coll. Sci. Teach. 2008; 37:71-73.

[8]. Julio Frenk, Lincoln Chen, Zulfiqar A Bhutta, Jordan Cohen, Nigel Crisp, Timothy Evans et al. Health professionals for a new century: transforming education to strengthen health systems in an interdependent world: The Lancet Commissions Report. 2010; 376; 1943-44. Available on www.thelancet.com. (Cited on 31.5.2012).

[9]. Nagaswami S. Vasan, David O. DeFouw, Bart K. Holland. Modified Use of Team-Based Learning for Effective Delivery of Medical Gross Anatomy and Embryolog.y Anat Sci Ed. 2008;1:3-9.

[10]. Harden, R.M. \& Davis, M.H. The continuum of problem-based learning. Medical Teacher, 1998; 20: 317 - 322

[11]. Harden, R.M., Crosby, J., Davis, M.H., Howie, P.W. \& Struthers A.D. Task-based learning: The answer to integration and problembased learning in the clinical years. Medical Education. 2000;34:391 - 397.

[12]. Zubair Amin, Khoo Hoon Eng. World Scientific. Basics in Medical Education. 361-62.

[13]. Clark, M., Nguyen, H., Bray, C., \& Levine, R. Team-based learning in an undergraduate nursing course. Journal of Nursing Education. 2008; 47:111-117.

[14]. Haidet, P., Schneider, V., \& Onady, G. Research and scholarship: Team based learning in health professions education. In L. Michaelsen, D. Parmelee, K. McMahon, \& R. Levine (Eds.), Team-based learning for health professions education: A guide to using small groups for improving learning. Sterling, VA: Stylus Publishing. 2008; 117-130.

[15]. McInerney, M., \& Fink, L. Team-based learning enhances long-term retention and critical thinking in an undergraduate microbial physiology course. Microbial Education. 2003; 4(1): 3-12.

[16]. Touchet, B., \& Coon, K. A pilot use of team-based learning in psychiatry resident psychodynamic psychotherapy education. Academic Psychiatry.2005;29: 293-296.

[17]. Zgheib NK, Simaan JA, Sabra R. Using team based learning to teach pharmacology to second year medical students improves student performance. Med Teach 2009; 32(2):130-135.

[18]. Michaelsen LK, Sweet M. Fundamental principles and practices of team based learning. In: Michaelsen LK, Parmelee DX, McMahon KK, Levine RE (Editors). Team-Based Learning for Health Professions Education: A Guide to Using Small Groups for Improving Learning. Sterling, VA: Stylus Publishing, LLC. 2007; 9-34.

[19]. Hernandez, S. Team learning in a marketing principles course: Cooperative structures that facilitate active learning and higher level thinking. Journal of Marketing Education. 2002; 24:73-85.

[20]. Thackeray, R., \& Wheeler, M. Innovations in social marketing education: A team-based learning approach. Social Marketing Quarterly. 2006; 3(3):42-48.

[21]. Hubert Wiener, Herbert Plass, and Richard Marz. Team-based Learning in Intensive Course Format for First-year Medical Students. Croat Med J. 2009 February; 50(1): 69-76. 


\section{Plan of Work}

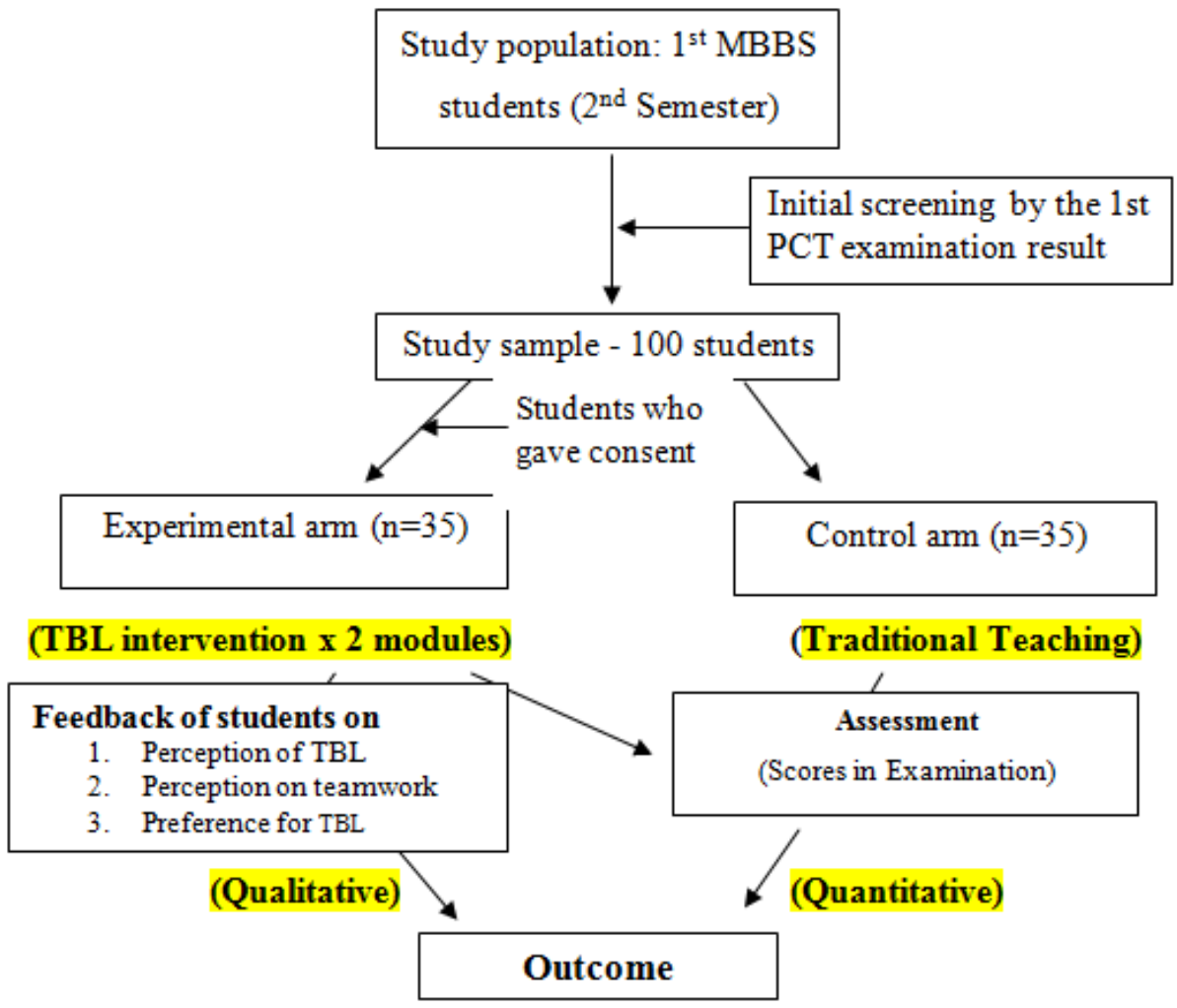

Flow diagram of Implementation Strategy

\begin{tabular}{|c|c|c|}
\hline $\begin{array}{l}\text { Orientation to students of TBL, taking } \\
\text { consent, forming groups. } \\
\text { Describing } 2 \text { modules with leaming } \\
\text { objective }\end{array}$ & $\approx 2$ weeks & $\begin{array}{l}\text { Students must refer material, read the } \\
\text { topic as per the leaming objectives } \\
\text { (out of the class activity) }\end{array}$ \\
\hline & $1^{\text {st }}$ Session & \\
\hline $\begin{array}{l}\text { TBL session: Test of } 10 \text { MCQ's (Level } \\
\text { I \& II) } \\
\text { taken in Groups - GRAT } \\
\text { (in class activity) }\end{array}$ & 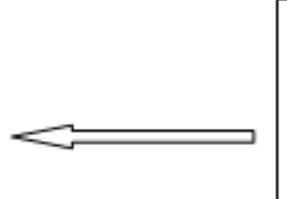 & $\begin{array}{l}\text { TBL session: Test of } 10 \text { MCQ's (Level } \\
\text { I \& II) } \\
\text { taken individually - IRAT } \\
\text { (in class activity) }\end{array}$ \\
\hline $\begin{array}{l}\text { taken in Groups - GRAT } \\
\text { (in class activity) }\end{array}$ & $2^{\text {nd }}$ Session & \\
\hline $\begin{array}{l}\text { Discussion of the case in groups followed } \\
\text { by discussion of the questions among } \\
\text { groups }\end{array}$ & $\Longrightarrow$ & $\begin{array}{l}\text { Clarifications by the facilitator with } \\
\text { the help of audio-visual aids }\end{array}$ \\
\hline
\end{tabular}


Team Based Learning: A controlled trial of Active learning in Large Group Setting.

Table No. 1: Students' response on Perception of TBL in \% $(n=35)$.

( $\mathrm{SD}=$ Strongly disagree, $\mathrm{D}=$ Disagree, $\mathrm{N}=$ Neutral, $\mathrm{A}=$ Agree, $\mathrm{SA}=$ Strongly agree)

\begin{tabular}{|c|c|c|c|c|c|c|}
\hline $\mathrm{S} N$ & Items & SD & $\mathrm{D}$ & $\mathrm{N}$ & A & SA \\
\hline 1 & TBL helped me prepare for course content & 0 & 0 & 0 & 83 & 17 \\
\hline 2 & $\begin{array}{l}\text { TBL helped me increase my understanding of course } \\
\text { material }\end{array}$ & 0 & 0 & 0 & 79 & 21 \\
\hline 3 & The group discussion allowed me to correct my mistakes. & 0 & 0 & 0 & 59 & 41 \\
\hline 4 & Learning issues helped me to focus on core information. & 0 & 0 & 33 & 48 & 19 \\
\hline 5 & $\begin{array}{l}\text { I learned the useful additional information during the } \\
\text { TBL session }\end{array}$ & 0 & 0 & 0 & 76 & 24 \\
\hline 6 & $\begin{array}{l}\text { Discussions of the TBL learning issues were useful } \\
\text { learning activities }\end{array}$ & 0 & 0 & 23 & 59 & 18 \\
\hline 7 & $\begin{array}{l}\text { The TBL format was helpful in developing my } \\
\text { information synthesizing skills }\end{array}$ & 0 & 0 & 35 & 53 & 12 \\
\hline 8 & Individual tests (IRAT) were useful learning activity & 0 & 0 & 0 & 67 & 33 \\
\hline
\end{tabular}

Table No. 2: Students' response on Perception on Teamwork in $\%(n=35)$.

\begin{tabular}{llcllcc}
\hline S N & \multicolumn{1}{c}{ Items } & SD & D & N & A & SA \\
\hline $\mathbf{1}$ & My team worked well together & 0 & 0 & 0 & 08 & 92 \\
$\mathbf{2}$ & $\begin{array}{l}\text { There was mutual respect for other teammates } \\
\text { viewpoints during TBL }\end{array}$ & 0 & 0 & 0 & 79 & 21 \\
$\mathbf{3}$ & $\begin{array}{l}\text { I have positive attitude about working with my peers } \\
\mathbf{4}\end{array}$ & 0 & 0 & 0 & 23 & 77 \\
$\mathbf{5}$ & $\begin{array}{l}\text { Most students were attentive during TBL sessions } \\
\mathbf{6}\end{array}$ & 0 & 0 & 0 & 17 & 83 \\
\hline & $\begin{array}{l}\text { The ability to collaborate with my peers is necessary if I } \\
\text { am to be successful as a student }\end{array}$ & 0 & 0 & 32 & 51 & 17 \\
$\mathbf{7}$ & $\begin{array}{l}\text { Solving problems in a group was an effective way to } \\
\text { practice what I had learned }\end{array}$ & 0 & 0 & 0 & 72 & 28 \\
\hline
\end{tabular}

Table No. 3: Students' response on Preference for TBL in \% $(n=35)$.

\begin{tabular}{lllllll}
\hline S N & \multicolumn{1}{c}{ Items } & SD & D & N & A & SA \\
\hline $\mathbf{1}$ & I have completed 100\% of required reading & 0 & 0 & 23 & 77 & 0 \\
$\mathbf{2}$ & I generally felt prepared for individual tests & 0 & 0 & 14 & 70 & 16 \\
$\mathbf{3}$ & I learnt better from lecture than small group (TBL) & 23 & 60 & 12 & 0 & 0 \\
$\mathbf{4}$ & I learnt useful additional information during TBL session & 0 & 0 & 08 & 64 & 28 \\
$\mathbf{5}$ & TBL helped me prepare for course examination & 0 & 0 & 26 & 74 & 0 \\
$\mathbf{6}$ & The group discussion improved understanding of the concepts. & 0 & 0 & 0 & 17 & 83 \\
$\mathbf{7}$ & I had positive attitude about working with my peers & 0 & 0 & 28 & 33 & 39 \\
$\mathbf{8}$ & Solving problems in a group was an effective way to learn & 0 & 0 & 0 & 28 & 72 \\
& Physiology & & & & & \\
$\mathbf{9}$ & I paid attention most of the time during TBL sessions & 0 & 0 & 0 & 88 & 12 \\
\hline
\end{tabular}

Table No. 4: Students performance in Both Groups.

\begin{tabular}{|c|c|c|c|}
\hline \multirow[t]{2}{*}{ Variable } & \multicolumn{2}{|c|}{ Mean scores (out of 56) } & \multirow{2}{*}{$\begin{array}{c}\text { Effect } \\
\text { (p value) }\end{array}$} \\
\hline & Study Gp $(n=35)$ & Control Gp $(n=35)$ & \\
\hline $\begin{array}{l}\text { Scores in } \\
\text { Examination }\end{array}$ & $\begin{array}{c}39.52 \pm 7.31 \\
(70.57 \%)\end{array}$ & $\begin{array}{c}35.45 \pm 6.48 \\
(63.30 \%)\end{array}$ & $0.132 *$ \\
\hline
\end{tabular}

\footnotetext{
* Not significant (significant at $\mathrm{p}<0.05$ )
} 